\title{
Gynecologic oncology in Mexico and the Mexican College of Gynecologic Oncologists
}

\author{
Guillermo Herbert-Nuñez, Querétaro, Mexico; Victor Vargas-Hernández, Ciudad de México, Mexico; \\ Eva Ruvalcaba-Limon (D) , Ciudad de México, Mexico and David Cantu-de-León, Mexico City, Mexico
}

Gynecologic malignancies are a major healthcare problem in countries with emerging economies such as Mexico. However, the clinicians responsible for the management of patients with these tumors remains a topic of debate. Over the years, at least in Mexico, care for gynecologic oncology patients has been by surgical oncologists due to the fact that gynecologic oncology, as a specialty, was not recognized by university programs and curriculae were not formally established. In the 1980s, due to the need to train physicians dedicated to the care of patients with gynecologic cancers, 1 year courses were initiated and 3 year residency programs in gynecologic oncology were established.

In 2002, an initiative by a group of gynecologic oncology graduates at the National Cancer Institute of Mexico (INCAN), under the tutelage of the late Professor Carlos M. Lopez Graniel, led to the formation of the Mexican College of Gynecologic Oncologists. Approval was given by renowned physicians Jaime de la Garza Salazar MD, who was the institute director, Thomas F. Purdon $\mathrm{MD}$ as honorary member of the American College of Obstetricians and Gynecologists (USA), Ernesto Castelazo Morales MD as representative of the Mexican Federation of Gynecology and Obstetrics, and various other leaders in the field.

The purpose of the college was to bring together, from an academic point of view, physicians dedicated to this area of medicine and share experiences and develop collaborations to strengthen research in the field. The first board of directors was presided over by Professors Carlos M. López Graniel (t), Guillermo Sidney Herbert Núñez MD as Vice President, and Alfonso Dueñas González as Secretary. In 2004, it was formally constituted as a College before the Mexican authorities.

The specialty was formally recognized by the National Autonomous University of Mexico (UNAM) in 2007 and 3 years

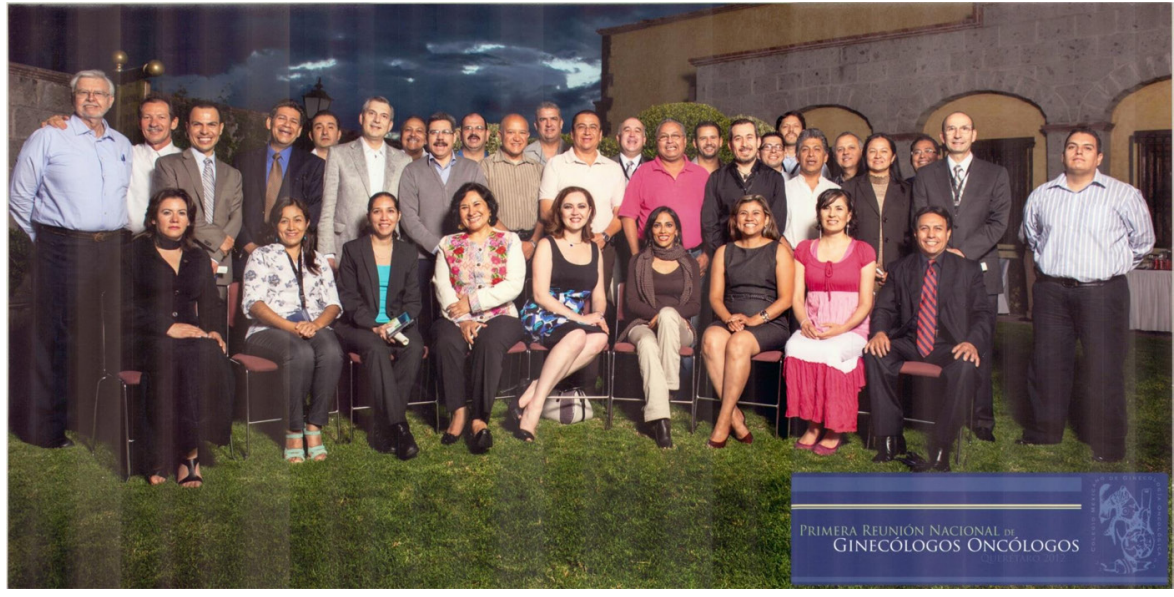

Annual Meeting in 2012. later by the Mexican Council of Oncology. Currently, there are at least 10 branches of the institute in Mexico that train gynecologic oncology specialists. During the initial years of the College, presence and participation in national congresses of gynecology and obstetrics, in conjunction with the Mexican Association of Mastology. Over the years the number of members has increased, and in 2012 there was the First National Meeting of Gynecologic Oncologists in Queretaro with an attendance of physicians from around the country. From this date, the meeting has been held every 2 years and from 2018 the International Congress is on an annual basis, with the last meeting in November 2021 in a 100\% virtual forum

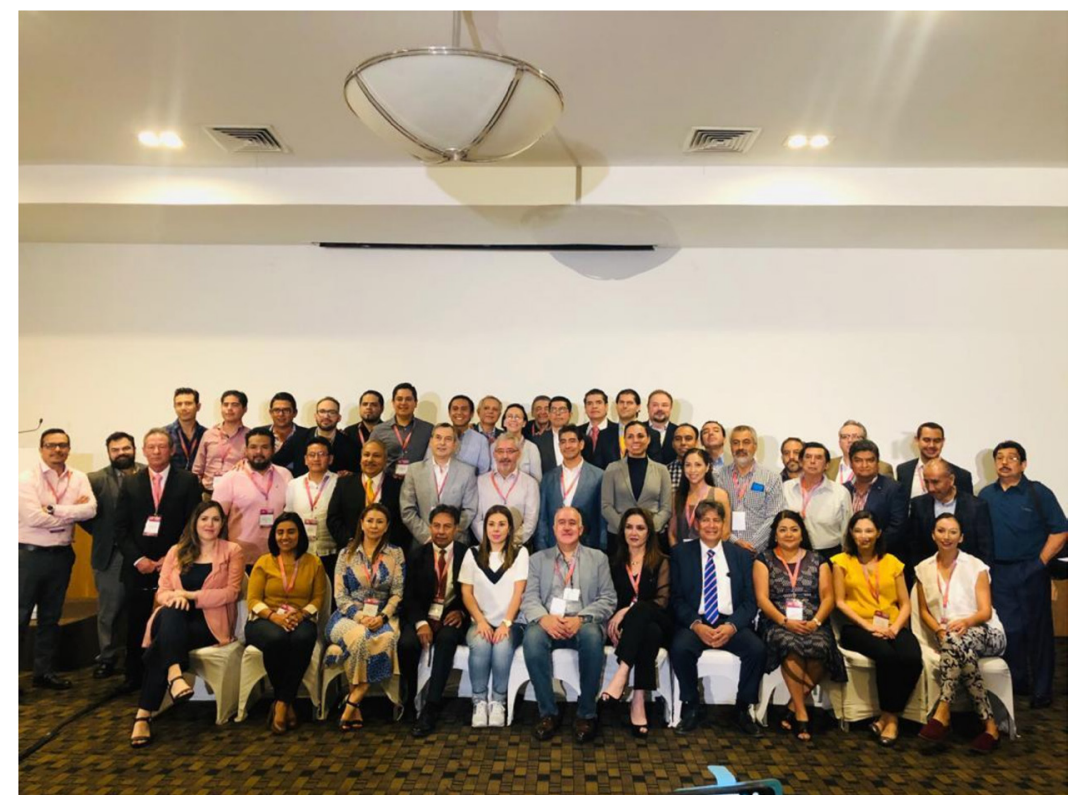

Meeting of the College in Querétaro, 2019. 


\section{Corners of the world}

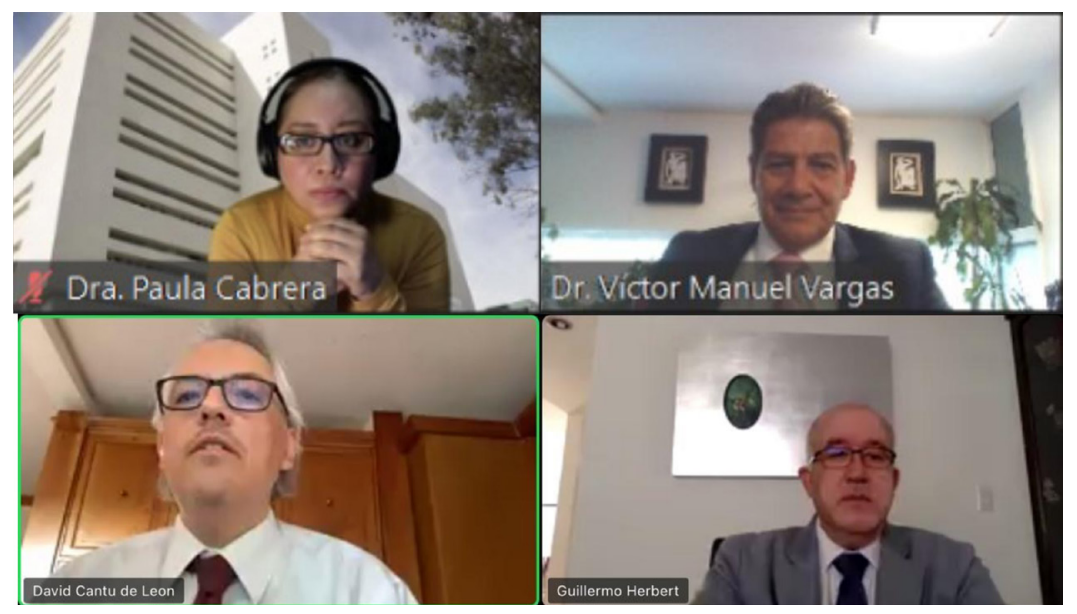

2021 Virtual Meeting because of the pandemic.

due to the COVID-19 pandemic, with more than 200 attendees from Mexico and Central America.

Our group has achieved the goals of establishing regular meetings, bimonthly sessions and participation in international meetings, and we aim to have more than
70 active members and 220 non-active members by 2023.

Correspondence to Dr David Cantu-de-León, Direction of Research, Instituto Nacional de Cancerologia, Mexico City 14080, Mexico; Dcantude@ gmail.com

Contributors GH and VV provided information and performed a final review of the document.
ERL reviewed the information and final version of the document. DCL compiled the information and performed the final review.

Funding The authors have not declared a specific grant for this research from any funding agency in the public, commercial or not-for-profit sectors.

Competing interests None declared.

Patient consent for publication Not applicable.

Provenance and peer review Commissioned; internally peer reviewed.

C IGCS and ESGO 2022. No commercial re-use. See rights and permissions. Published by BMJ.

(D) Check for updates

To cite Herbert-Nuñez G, Vargas-Hernández V, Ruvalcaba-Limon E, et al. Int J Gynecol Cancer Published Online First: [please include Day Month Year]. doi:10.1136/ijgc-2022-003344

Accepted 9 February 2022

Int J Gynecol Cancer 2022;0:1-2.

doi:10.1136/ijgc-2022-003344

\section{ORCID iD}

Eva Ruvalcaba-Limon http://orcid.org/0000-00024645-3019 